\title{
Thorned heart. Description of a near-fatal cardiac embolism after percutaneous Vertebroplasty
}

\author{
Federica Pigna, ${ }^{1}$ Simone Calamai, ${ }^{2}$ Francesco Scioscioli, ${ }^{1}$ Lorenzo Buttarelli, ${ }^{3}$ \\ Francesco Nicolini, ${ }^{4}$ Gianfranco Cervellin ${ }^{5}$
}

${ }^{1}$ Emergency Department, University Hospital of Parma; ${ }^{2}$ Postgraduate Emergency Medicine School, University of Parma; ${ }^{3}$ Department of Radiology, University Hospital of Parma; ${ }^{4}$ Cardiac Surgery Unit, University Hospital of Parma, Parma; ${ }^{5}$ Academy of Emergency Medicine and Care (AcEMC), Pavia, Italy

\begin{abstract}
Cement extravasation is a rather common complication of vertebroplasty, which can be observed in up to $30-40 \%$ of patients undergoing this procedure, further associated with venous leakage occurring in up to $24 \%$ of cases. Pulmonary embolism may eventually develop once the cement migrates within the pulmonary artery, and is the most common complication of cement extravasation (involving $\sim 4.6 \%$ of patients). Intra-cardiac cement embolism is considerably less frequent, but is a potentially fatal complication, mostly managed with cardiac surgery. We describe here a rare case of near-fatal cardiac cement embolism, with a large fragment perforating the right ventricle and reaching the pericardium, who presented to the Emergency Department (ED) for syncope. The patient, who displayed this severe complication after a vertebroplasty procedure performed for osteoporotic compression fracture, needed cardiac surgery.
\end{abstract}

\section{Introduction}

Percutaneous Vertebroplasty (PVP), a minimally invasive procedure introduced by Gailbert et al. in 1987, is aimed at treating

\footnotetext{
Correspondence: Gianfranco Cervellin, Academy of Emergency Medicine and Care (AcEMC), via Maugeri, 27100 Pavia (PV), Italy Tel.: +39.349.0669585

E-mail: gianfranco.cervellin@gmail.com

Key words: Vertebroplasty; cardiac embolism; osteoporotic compression fractures; acrylic cement extravasation.

Conflict of interest: No one. This work was not supported by any grant.

Ethics approval and consent to participate: The manuscript does not contain any elements that would allow the recognition of the patient.

Received for publication: 6 December 2019

Accepted for publication: 26 March2020.

This work is licensed under a Creative Commons Attribution 4.0 License (by-nc 4.0).

${ }^{\circ}$ Copyright: the Author(s), 2020

Licensee PAGEPress, Italy

Emergency Care Journal 2020; 16:8739

doi:10.4081/ecj.2020.8739
}

vertebral compression fractures. ${ }^{1}$ This procedure consists in injection of a type of acrylic cement (generally polymethylmethacrylate) into the vertebral body through its pedicles, for partially restoring the vertebral height and stabilizing the trabeculae, thus alleviating pain and discomfort. ${ }^{2,3}$ Originally developed for neoplastic fractures, PVP has been then extended to management of osteoporotic fractures and has achieved worldwide diffusion after publication of some case series, despite lack of substantial evidence $^{4-8}$ and with only one randomized trial proving some benefits. ${ }^{9}$ These findings have also raised some ongoing ethical and organizational issues, ${ }^{10,11}$ since several adverse events associated with PVP have been described, mainly encompassing osteomyelitis, cord compression, thecal sac injury, respiratory failure due to pulmonary cement emboli, and cardiac emboli, less frequently. $8,12-14$

We describe here a rare case of near-fatal cardiac cement embolism, needing cardiac surgery, after a vertebroplasty procedure performed for osteoporotic compression fracture.

\section{Case Description}

An 85-year-old woman presented to the Emergency Department (ED) for syncope developed few hours after she underwent percutaneous vertebroplasty on the fourth lumbar vertebra (L4) for osteoporotic compression fracture associated with pain resistant to conservative treatment. After the syncopal episode, the patient complained for headache and chest pain radiated to the neck.

The medical history was positive for hypothyroidism and mild Alzheimer's disease. The patient was an active smoker, was taking low dose aspirin, as primary cardiovascular prevention, without any recorded event in his history. She was also taking thyroxine and donepezil, whilst no allergies were reported.

Blood pressure upon ED admission was $110 / 60 \mathrm{mmHg}$, heart rate $80 \mathrm{bpm}$, respiratory rate 14 breaths per minute and peripheral oxygen saturation $97 \%$. No fever and no other clinically meaningful findings could be recorded.

During the ED visit the patient had an additional syncope associated with hypotension (i.e., 90/50 $\mathrm{mmHg}$ ), accompanied with cape cyanosis and bladder and fecal incontinence. Urgent blood testing revealed some abnormal results, as follows: White Blood Cells (WBC) $17.480 / \mu \mathrm{L}$, glucose $220 \mathrm{mg} / \mathrm{dL}$, cardiac troponin I $1137 \mathrm{ng} / \mathrm{L}$ (upper reference limit, $10.5 \mathrm{ng} / \mathrm{L}$ in women). The Electrocardiogram (ECG) showed mild sinus tachycardia (105 $\mathrm{bpm}$ ), without ischemic modifications. Due to the clinical worsening, persistence of chest pain and observation of pericardial effusion with bed-side ultrasonography, the patient was suspected as having aortic dissection, so that she underwent computed angiog- 
raphy (Angio-CT). This investigation confirmed the presence of pericardial effusion (maximal width, $19 \mathrm{~mm}$ ) and linear hyperdense material into the inferior vena cava and within the Right Ventricle (RV). Based on these findings, a Cardiac Computed Tomography (cCT) was scheduled, which confirmed the presence of a radiopaque needle-like body lodged inside the RV, just $10 \mathrm{~mm}$ below the valvular plane. This abnormal finding was identified as likely being a fragment of cement embolized during the PVP. Briefly, the "needle" passed through the basal-inferior wall of RV, reaching the pericardium (Figure 1; Figure 2) and causing hemopericardium thus promoting cardiac tamponade. A cardiac surgeon was immediately alerted, and the patient underwent cardiac surgery for removing the cement fragment and repairing the RV (Figure 3). Aspirin was stopped before surgery. After being removed, the 'needle' was found to be $3.5 \mathrm{~cm}$-long, with a $\sim 2-3$ $\mathrm{mm}$ width, as shown in Figure 4. The post-operative course was complicated by anemia, requiring blood transfusions (3 Units of

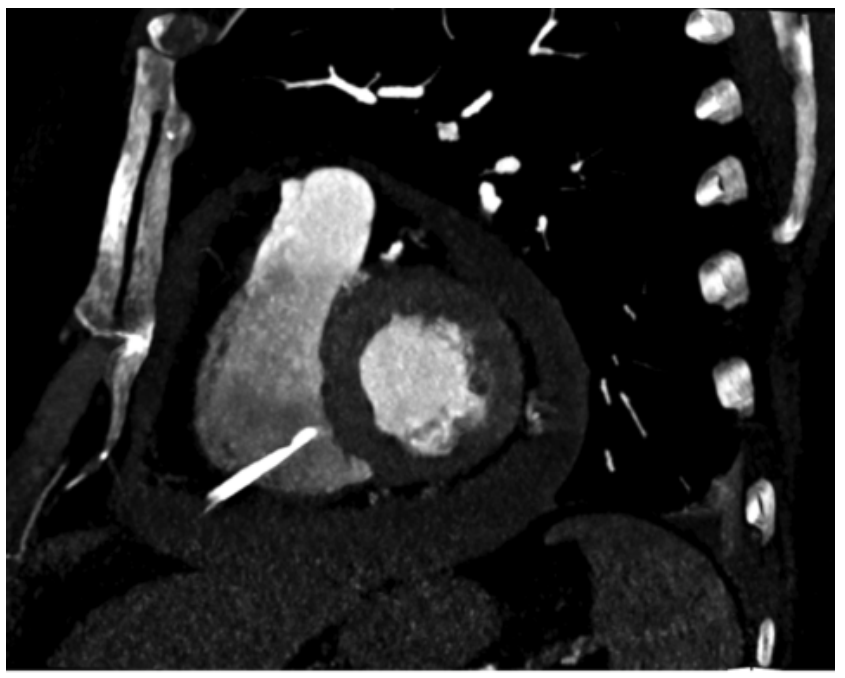

Figure 1. cCT image showing a needle-like hyperdense body inside the right ventricle, penetrating the ventricular wall and reaching pericardial space.

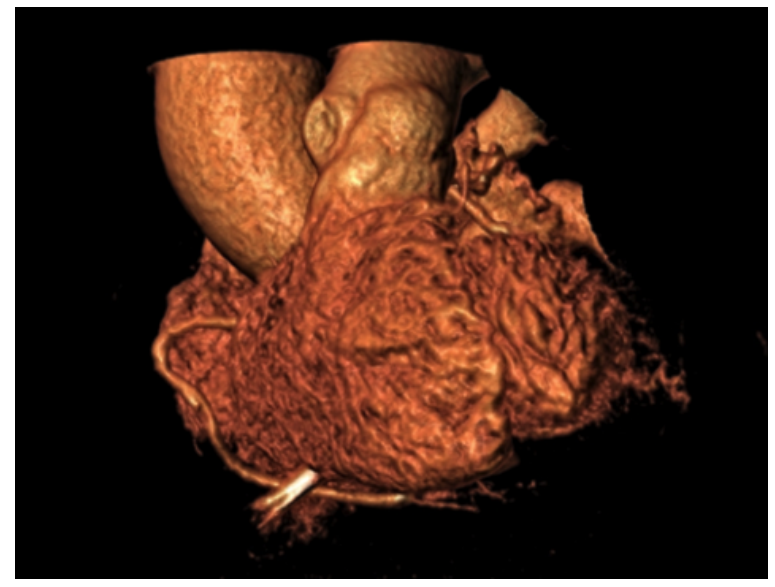

Figure 2. 3D reconstruction of cCT image showing a needle-like hyperdense body inside the right ventricle, penetrating the ventricular wall and reaching pericardial space. . concentrated red blood cells), and by an episode of delirium, needing neuroleptics (i.e., quetiapine). On the 10th day after surgery, the patient was then transferred to the rehabilitation clinic, where the ensuing clinical course was clinically favorable.

\section{Discussion}

Bone cement leakage is of particular concern among the various possible complications of PVP, since it can lead to canal stenosis, as well as cord ${ }^{15,16}$ and nerve root $^{17}$ compressions.

Cement extravasation is indeed a rather frequent common complication of vertebroplasty, which can be observed in up to 30$40 \%$ of patients undergoing this procedure, ${ }^{18}$ further associated with venous leakage occurring in up to $24 \%$ of cases. ${ }^{12}$ It usually develops when the injected acrylic cement is not sufficiently polymerized, so that it may leak into the external vertebral venous

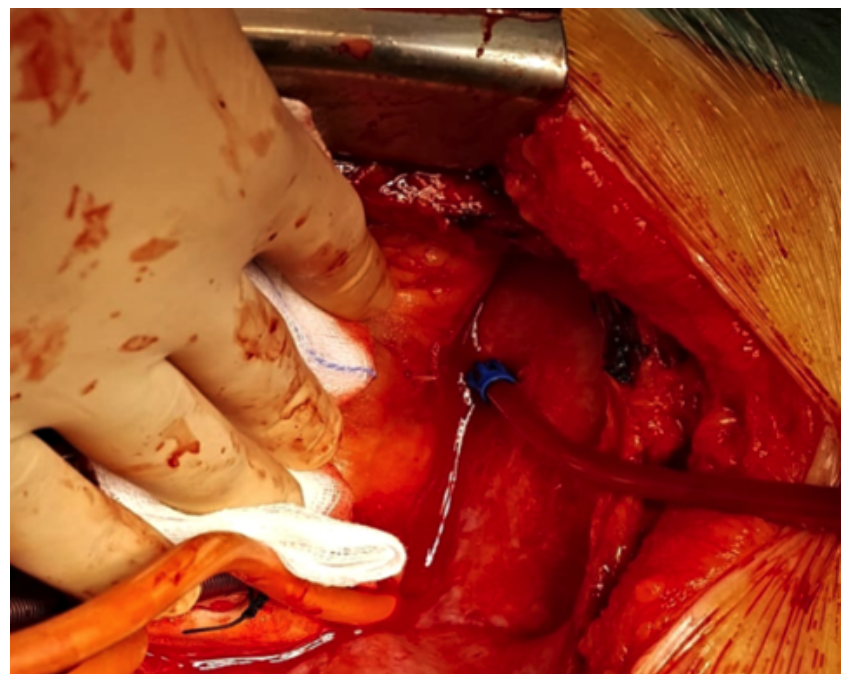

Figure 3. Intra-operatory picture showing the tip of the foreign body spurting out the inferior wall of the right ventricle.

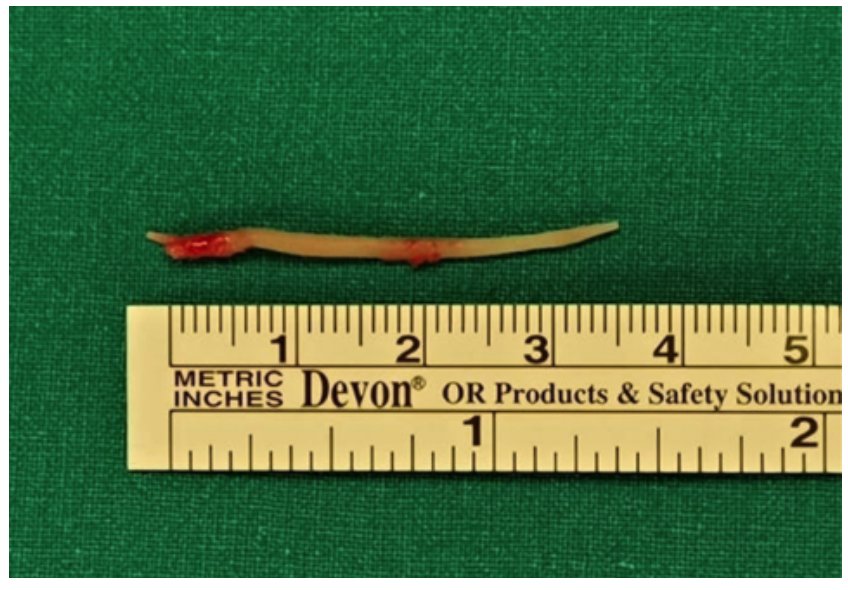

Figure 4. The extracted cement needle-like fragment after surgery was completed. 
plexuses, then migrating into the Inferior Vena Cava (IVC). Pulmonary embolism may eventually develop once the cement migrates within the pulmonary artery, and can hence be considered the most frequent complication of cement extravasation (involving $\sim 4.6 \%$ of patients), often being asymptomatic (due to the small size of the emboli), but occasionally hemodynamically compromising. ${ }^{12,13}$ Intra-cardiac cement embolism is considerably less frequent, but is a potentially fatal complication, mostly managed with cardiac surgery. ${ }^{14}$ Only rarely cardiac embolism has been successfully managed with endovascular procedure. ${ }^{19}$ Surprisingly, late clinical manifestations of cardiac injury due to cement embolism have even been described. ${ }^{20}$

Although reliable studies addressing the potential risk factors of cement embolism are almost lacking, intravertebral cleft, cortical disruption, low cement viscosity and high volume of injected cement have been implicated, whilst age, gender, fracture type, operation level do not appear to be significant determinants..$^{21,22}$

\section{Conclusions}

In line with a recent Cochrane Review, ${ }^{8}$ we endorse the concept that patients should be informed on the evidence failing to support substantial benefits of vertebroplasty but highlighting its potential complications and side effects. Emergency physicians should also acknowledge the risk of cardiac or pulmonary complications of PVP whenever facing patients with syncope, chest pain, hypotension or dyspnea after being managed with this procedure for vertebral compression fractures.

\section{References}

1. Gailbert P, Deramond H, Rosat P, Le Gars D. Preliminary note on the treatment of vertebral angioma by percutaneous vertebroplasty. Neurochirurgie 1987;2:166-8

2. Mazumdar A, Gilula LA. Relief of radicular pain in methastatic disease by vertebroplasty. Acta Radiologica 2010;51:17982. DOI: $10.3109 / 02841850903431148$.

3. Chen LH, Hsieh MK, Niu CC, et al. Percutaneous vertebroplasty for pathological vertebral compression fractures secondary to multiple myeloma. Arch Orthop Trauma Surg 2012;132:759-64. DOI: 10.1007/s00402-012-1474-y.

4. Buchbinder R, Osborne RH, Ebeling PR, et al. A randomized trial of vertebroplasty for painful osteoporotic vertebral fractures. N Engl J Med 2009;361:557-68. DOI: 10.1056/NEJ Moa0900429.

5. Kallmes DF, Comstock BA, Heagerty PJ, et al. A randomized trial of vertebroplasty for osteoporotic spinal fractures. N Engl J Med 2009;361:569-79. DOI: 10.1056/NEJMoa0900563.

6. Firanescu CE, de Vries J, Lodder P, et al. Vertebroplasty versus sham procedure for painful acute osteoporotic vertebral compression fractures (VERTOS IV): randomised sham controlled clinical trial. BMJ 2018;361:k1551. DOI: https://doi.org/ 10.1136/bmj.k1551.

7. Lou S, Shi X, Zhang X, et al. Percutaneous vertebroplasty versus non-operative treatment for osteoporotic vertebral compression fractures: a meta-analysis of randomized controlled trials. Osteop Int 2019;30:2369-80. DOI: 10.1007/s00198-01905101-8.

8. Buchbinder R, Johnston RV, Rischin KJ, et al. Percutaneous vertebroplasty for osteoporotic vertebral compression fracture. Cochrane Database Syst Rev 2018;4:CD006349. DOI: 10.1002/14651858.CD006349.pub3.

9. Clark W, Bird P, Gonski P, et al. Safety and efficacy of vertebroplasty for acute painful osteoporotic fractures (VAPOUR): a multicentre, randomised, double-blind, placebo-controlled trial. Lancet 2016;388:1408-16. DOI: 10.1016/S01406736(16)31341-1.

10. Carragee EG. The vertebroplasty affair: the mysterious case of the disappearing effect size. Spine J 2010;10:191-2. DOI: 10.1016/j.spinee.2010.01.002.

11. Wulff KC, Miller FG, Pearson SD. Can coverage be rescinded when negative trial results threaten a popular procedure? The ongoing saga of vertebroplasty. Health Aff (Millwood) 2011;30:2269-76. doi: 10.1377/hlthaff.2011.0159.

12. Luetmer MT, Bartholmai BJ, Rad AE, Kallmes DF. Asymptomatic and unrecognized cement pulmonary embolism commonly occurs with vertebroplasty. AJNR Am J Neuroradiol 2011;32:654-7. doi: 10.3174/ajnr.A2368.

13. Kim YJ, Lee JW, Park KW, et al. Pulmonary cement embolism after percutaneous vertebroplasty in osteoporotic vertebral compression fractures: incidence, characteristics, and risk factors. Radiol 2009;251:250-9. doi: 10.1148/radiol.2511080854.

14. Audat ZA, Alfawareh MD, Darwish FT, Alomari AA. Intracardiac leakage of cement during kyphoplasty and vertebroplasty: a case report. Am J Case Rep 2016;17:326-30. doi: 10.12659/AJCR.897719.

15. Teng MM, Cheng H, Ho DM, Chang CY. Intraspinal leakage of bone cement after Vertebroplasty: a report of 3 cases, Am J Neuroradiol 2006;27:224-9.

16. Harrington KD. Major neurological complications following percutaneous vertebroplasty with polymethylmethacrylate: a case report, J Bone Joint Surg Am 2001;83:1070-3.

17. Alvarez L, Perez-Higueras A, Quinones D, et al. Vertebroplasty in the treatment of vertebral tumors: postprocedural outcome and quality of life. Eur Spine 2003;12:356-60. doi: 10.1007/s00586-003-0525-z.

18. Laredo JD, Hamze B. Complications of percutaneous vertebroplasty and their prevention. Skeletal Radiol 2004;33:493-505.

19. Park JS, Kim J, Lee Y, et al. Intra-cardiac embolism of a large bone cement material after percutaneous vertebroplasty removed through a combination of an endovascular procedure and an inferior vena cava exploration: a case report. J Korean Med Sci 2018;33:e141. doi: 10.3346/jkms.2018.33.e141.

20. Prokop A, Hägele M, Pfeilsticker U, et al. [Pericardial perforation 2.5 years after kyphoplasty. A rare complication after cement extravasation]. Unfallchirurg 2013;116:80-4. [Article in German]. doi: 10.1007/s00113-011-2136-1.

21. Zhan Y, Jiang J, Liao H, et al. Risk factors for cement leakage after vertebroplasty or kyphoplasty: a meta-analysis of published evidence. World Neurosurg 2017;101:633-42. doi: 10.1016/j.wneu.2017.01.124

22. Janssen I, Ryang YM, Gempt J, et al. Risk of cement leakage and pulmonary embolism by bone cement-augmented pedicle screw fixation of the thoracolumbar spine. Spine J 2017;17:837-44. doi: 10.1016/j.spinee.2017.01.009. 